\title{
Japanese Science and Technology Basic Plan: A Perspective of Policy Process
}

\author{
Yukihide Hayashi* \\ Center for Research and Development Strategy, Japan Science and Technology Agency, Tokyo 102-0076, Japan
}

\begin{abstract}
The Japanese government formulates the Science and Technology Basic Plan every five years based on the Science and Technology Basic Law, and indicates the future direction of Japan's science and technology. This paper describes its history, significance, and decision process of this Science and Technology Basic Plan. Then this paper describes the characteristics of the previous five plans, contributions to Japanese science and technological activities, and its challenges for the future.

In the formulation of the Science and Technology Basic Plan, the role of the Council for Science and Technology Policy has been significant. However, after establishing Shinzo Abe administration, the inclination to global innovation has been emphasized in Japan as well, the Council for Science and Technology Policy was renamed the Council for Science, Technology and Innovation, and the midterm and annual strategies centered on innovation have also been prepared. This paper described these movements.

Japan suffers from population decline and the increase in governmental deficits, and there is also a tendency towards weakness in science and technology innovation. To formulate more suitable science and technology basic plans will revitalize and strengthen Japan's science and technology innovation.
\end{abstract}

\section{Keywords}

science and technology agency; science and technology basic law; science and technology basic plan; five years plan; council for science and technology policy; the council for science; technology and innovation; Shinzo Abe; Japan

\footnotetext{
"Corresponding author at: hayashi@lifesci-found.com
} 


\section{History of Science and Technology Basic Plan}

\subsection{Establishment of the Science and Technology Agency}

In 1956, the Science and Technology Agency was established under the Prime Minister's office of the Japanese Government for the purpose of promoting science and technology. In Japan, science and technology activities were carried out quite before World War II, and the competent authority for each industry promoted technological development with their own laboratories and subsidiaries. For instance, the Ministry of Education developed basic research, the Ministry of International Trade and Industry developed industrial technology, and the Ministry of Agriculture and Forestry developed agricultural technology. The Science and Technology Agency was established for promoting unitary development of atomic energy which was a brand-new field at the time, and also for conducting science and technological activities with integrity among Ministries and Agencies concerned with science and technology.

To promote comprehensive coordination of science and technology, in 1959 the "Science and Technology Council" was set up as an advisory body for Prime Minister under the Prime Minister's office, and the Science and Technology Agency became the secretariat of the Council. The first consultation to the Council from the Prime Minister was to establish the comprehensive and fundamental policies for the development of science and technology for next 10 years. In order to promote the development of science and technology which is required for the economic development and the improvement of the people's life from long-term perspective, the Council formulated the report which showed the comprehensive basic policy for the training of required human resources, the expansion and the development of research activities and measures for information distribution and others, and submitted it to the Prime Minister on October 1960. This report was the starting point of today's Science and Technology Basic Plan. After that, the Council had continually submitted reports for individual matters such as information science program, energy research development program and evaluation guideline, and reports for the mid to long term plan same as mentioned above.

However, there was a difficulty that although good reports were submitted, they were not carried out smoothly. The problem was that the legal basis of these reports was not clearly defined. Although the Chairman of the Science and Technology Council was the Prime Minister, the plenary session which the Prime Minister attended was usually held only once a year. Therefore, related Ministries and Agencies recognized the Council only as the advisory body of the Science and Technology Agency, and reports made by them did not have a strong binding authority.

\subsection{Enactment of Science and Technology Basic Law}

The turning point was the establishment of the Science and Technology Basic Law in 1995. In the background of this Law, Japan's basic research level lagged behind those of the major European countries and the US, the research environment of universities and national research institutes was substantially lower than those of the major countries in the world, there was not enough close coordination beyond organizational and expertise barrier, and young people were drifting away from science and technology activities. The purpose of this Law was to clarify the direction of science and technology promotion and its fundamental measures, and to promote relevant policies 
comprehensively, systematically and proactively. After deliberations in the Diet, the bill of this Law was passed unanimously in both the House of Representatives and the House of Councilors. The enacted Science and Technology Basic Law stated that the government must formulate the Science and Technology Basic Plan after discussion in the Science and Technology Council, which meant that the government had a legal obligation to formulate the basic plan. During the deliberation process of the bill, the supplementary resolution was adopted that the basic plan should be formulated as a five-year plan which foresaw approximately the next 10 years ahead. Based on this Law, the 1st Basic Plan was formulated and decided by the Cabinet in 1996.

\subsection{Establishment of the Council for Science and Technology Policy}

Even after legal basis was given to the basic plan and it was decided by the Cabinet, there were still inadequacies. These inadequacies were caused because of the status of the Science and Technology Agency and the Science and Technology Council in the government at that time. As the secretariat of the Science and Technology Council, the Science and Technology Agency needed to have stronger authority than other Ministries and Agencies to coordinate them. However, in the case of the Science and Technology Agency, it was just the external and subordinate bureau of the Prime Minister's Office, and seen as the lower government office compared to other Ministries such as the Ministry of Education or the Ministry of International Trade and Industry. After the reorganization of central government Ministries and Agencies in 2001, the Science and Technology Council was upgraded to the Council for Science and Technology Policy, and its secretariat was moved from the Science and Technology Agency to the Cabinet Office, therefore it became the headquarters of promoting science and technology from a higher place than other related Ministries and Agencies.

In the same year, the 2nd Basic Plan was formulated under the initiative of the Council for Science and Technology Policy. After that, the 3rd Basic Plan was formulated in 2006, the 4th Basic Plan was formulated in 2011, and the 5th Basic Plan was formulated in 2016.

\subsection{Rename to the Council for Science, Technology and Innovation}

In order to maintain an economy towards sustainable development and to create a society in which the people can realize richness and security, policies to intensify innovation have become more important. As mentioned above the Science and Technology Council was established in January 2001, but in response to the emphasis on innovation, it was renamed as the Council for Science, Technology and Innovation. This further strengthened the commander tower's function on science and technology policy.

\section{Formulation Process of the Science and Technology Basic Plan}

\subsection{Preparation stage}

Formulation process of the Science and Technology Basic Plan is briefly explained here. After the previous Basic Plan is decided by the Cabinet, executive Ministries and Agencies such as the Ministry of Education, Culture, Sports, Science and Technology, the Ministry of Economy, Trade and Industry and the Ministry of Health, Labor and Welfare carry out their duties of science and technology in accordance 
with the Basic Plan. While doing so, they also follow up and analyze merits, challenges and inadequacies of the Basic Plan. The Council for Science, Technology and Innovation Policy (the name was changed from the Council for Science and Technology Policy in 2014), conducts interviews with these executive Ministries and Agencies appropriately, and develops ideas for the next Basic Plan.

After about three years from the decision of previous plan, related Ministries and Agencies discuss internally about the content of the next Basic Plan. When needed, discussion is made within each ministry's advisory body, or interviews with persons concerned are conducted. Aside from this, the Council for Science, Technology and Innovation independently from enforcement Ministries and Agencies conducts interviews with researchers and engineers, and requests a think tank to research and analyze in order to understand Japan's science and technology situation.

\subsection{Specialist committee}

About a year prior to the decision of the next plan, the Council for Science, Technology and Innovation establishes the specialist committee under itself. This specialist committee consists of approximately 20 persons who are mainly scholars and academic experts. Representatives of academic associations and industry associations are also invited to this committee. When the specialist committee formulates the draft of the plan, views on administrative matters are exchanged between the secretariat of the Council and related Ministries and Agencies. Related Ministries and Agencies have to make their best effort to reflect opinions of the related institutes and industry associations. After discussion and exchanging views on administrative matters in the specialist committee, the draft of the Basic Plan is decided.

\subsection{Cabinet decision}

After receiving the draft of the Basic Plan from the specialist committee, the Council for Science, Technology and Innovation examines it carefully and decides the report to the Prime Minister. The report is checked and finalized as the Science and Technology Basic Plan by the Cabinet. Before the Cabinet decision is made, it is important to make agreement with the ruling parties of the Diet (currently the Liberal Democratic Party and the Komeito), therefore during the formulation process, contacts and reports are appropriately made to them.

\section{Features of Previous Science and Technology Basic Plan}

Up until now, the Science and Technology Basic Plan based on the Science and Technology Basic Law has been formulated five times. Features of each plan are briefly explained here.

\subsection{The 1st Basic Plan (FY1996-FY2000)}

\subsubsection{Recognition of the situation}

Japan's research and development investment was decreased consecutively in FY1993 and FY1994, and the government's research and development investment as a percentage of GDP is still lower than that of the main countries in the world. The situation for promotion of science and technology continued to be harsh. Various research and development systems in Japan lacked flexibility and 
competitiveness, and restrictions are emerging. On the other hand, expectations for the role of science and technology to handle problems at home and abroad, and for basic research which had its value as intellectual property for all mankind to share, are increasing. Therefore, it is important for Japan to be the first to challenge unexplored field of science and technology.

\subsubsection{Concrete measures}

- Achieve a program to support 10,000 postdoctoral researchers by fiscal year 2000.

- Introduce a term-limited appointment system to public institutions in order to promote the mobility of researchers.

- Promote industry-academia-government collaboration.

- Increase competitive funds significantly.

- Conduct evaluation for research and development.

- Government's goal for research and development investment: The total investment of science and technology during the period of the plan was set to around 17 trillion yen.

\subsection{The 2nd Basic Plan (FY2001-FY2005)}

\subsubsection{Recognition of the situation}

In prospect of the 21st century, science and technology is expected to contribute to the development of economy and society, and to become a driving force of sustainable development of the world. Also, the power of science and technology is essential for dealing with population explosion, lack of water, food and energy resources, global warming and new infectious diseases, and to accomplish sustainable development all over the world.

In Japan, to overcome imminent problems including the decrease of industrial competitiveness, stagnation in job creation, and advancement of aging society, it is necessary to develop industry with high productivity and international competitiveness by achieving technological innovation to recover economic viability.

\subsubsection{Concrete measures}

- Promote in basic research, and make prioritization for next four fields: Life sciences, information and communication technology, environment sciences, nanotechnology and material sciences.

- Reform research and development system: Double the competitive funds. Introduce indirect expenses (30\%). Increase mobility of personnel. Promotion of independence for young researchers.

- Enhance industrial technology and reform the system of industrial-academic-government collaboration: Secure and foster personnel for promoting industrial-academic-government collaboration. Enrich database of research information and personnel. Set exclusive registered right to work and rules for transfer for government-owned patents. Establish a regional "science and technology cluster".

- Government's goal for research and development investment: The total investment of science and technology during the period of the plan was set to around 24 trillion yen.

\subsection{The 3rd Basic Plan (FY2006-FY2010)}

\subsubsection{Recognition of the situation}

- To achieve stable economic development while the population is declining, the birthrate 
is falling and the aging of the population is progressing, it is required to achieve value-added MONOZUKURI (Japanese way of manufacturing) by leveraging Japan's advantage. Science and technology is the source of competitiveness and improvement of productivity. It is required to achieve sustainable development by developing science and technology even more, and lead the results of development to constant innovation. Furthermore, people are becoming more concerned about security and safety because of the recent occurrence of security-threat situations for society and people, such as large-scale natural disasters and serious accident, or complication of the international security situation including terrorism. Science and technology is essential for resolving these kinds of problems.

- Our county's financial situation is worsening, therefore even more selection and concentration, and optimization is required for the government's research and development investment, including investment for preparation of advanced facilities.

\subsubsection{Concrete measures}

- Tactical prioritization of science and technology: Set priority in research and development fields for policy-oriented subjects. Set four priority fields of the 2nd Basic Plan and four fields to be promoted (energy, MONOZUKURI technology, social infrastructure, frontier technology). Furthermore, "strategic prioritized science and technology" is selected, and large-scale national projects are selected as "Key technology of national importance".

- Reform in the research and development system: Set a recruiting goal for female researchers. Enhance competitiveness of universities. Ensure introduction of an indirect expense of $30 \%$ to all competitive funds.

- Government's goal for research and development investment: The total investment of science and technology during the period of the plan was set to around 25 trillion yen.

\subsection{The 4th Basic Plan (FY2011-FY2015)}

\subsubsection{Recognition of the situation}

Right before deciding this plan, the Great East Japan Earthquake occurred on March 11, 2011. Around 20,000 people are either dead or missing, and the economy and society was severely and deeply damaged. Also, the Fukushima No.1 Nuclear Power Station accident caused a very serious situation, and possibility, and potential risk and management of science and technology became very important policy issues.

Japan is poor in natural resources, and science and technology and human resources are the important resources of this nation. However, while the trend is increasing among students to avoid choosing science and technology departments at college/university, Japan's excellent researchers and engineers are reaching the retirement age. Moreover, Japan's industrial competitiveness is still on a long, downward trend.

As a result of further progress in economic globalization, intensifying competition in emerging markets, and diversification of consumer needs, accelerated realization of innovation is becoming more important, innovation systems are greatly shifting to more open, global, and flat platforms. Also, as brain circulation is becoming prevalent around the world, international competition to acquire excellent human resources is becoming increasingly fierce. 


\subsubsection{Concrete measures}

- Integrated development of science and technology innovation policies.

- Further focus on the role of human resources and the organizations which support them.

- Realization of a policy to be created and promoted together with society.

- Government's goal for research and development investment : The total investment of science and technology during the period of the plan was set to around 25 trillion yen.

\subsection{The 5th Basic Plan (FY2016-FY2020)}

\subsubsection{Recognition of the situation}

After entering the 21st century, globalization is progressed due to the great progress in science and technology. Various social activities are now expanding beyond international borders. A new era is dawning, and the structure of the economy and society changes on a daily basis.

As the intellectual frontier expands, it becomes increasingly important to create a team of people with diverse specialization. Approach to open innovation is becoming important for companies, and open science is becoming the worldwide trend in scientific research. Meanwhile, networks are expanding on a global scale, which makes it essential to set new rules and codes of conduct for responding to security ramifications or protecting individual information. Furthermore, due to the development of new science and technology such as Internet of Things (IoT), robots, artificial intelligence (AI), regenerative medicine, brain science, a rethinking for the relationship between society and science and technology is required.

Japan has several issues including restriction on energy, resources, food and others, low birthrate and aging society. It is also required to respond appropriately to the risk of natural disaster or change in Japan's security environment, and to improve the resilience of our land and social function. And Japan must actively contribute to the peace and development of international society as a member of developed countries.

\subsubsection{Concrete measures}

- Create future industry and enact social reform: Japan needs to improve research and development which create non-continuous innovations, and make a series of initiatives for realizing the world's first "super smart society".

- Address economic and social issues: To address proactively issues, the government sets the key policy issues and promotes an approach to solve the issues.

- Reinforce fundamental strength: To promote to foster young researchers and support their activities, and to reform and improve functions of university/college.

- Establish a virtuous cycle of human resources, knowledge, and capital, aimed at innovation creation.

\subsubsection{Setting numerical goal}

In this plan, the numerical goals and major indicators as shown below are set in order to grasp the progress of the plan. It is first time that such concrete numerical goal is indicated in the formulation of the basic plan.

- Aim to make the adoption rate of female researchers over $30 \%$.

- Aim to increase the total number of scientific papers, and to make more than $10 \%$ of these 
papers to be among the top $10 \%$ of papers ranked by total citation number.

- Aim to increase the amount of money received by universities and national research institutes for joint research with private enterprises by $50 \%$.

- Aim to double the number of newly listed research and development type venture companies.

- Aim to increase the number of university's patent licensing agreements by $50 \%$.

- Government's goal for research and development investment : The total investment of science and technology during the period of the plan was set to around 26 trillion yen (approximately 236 billion US dollars when 1 US dollar is converted for 110 yen).

\section{Strengthening the Response to Innovation}

The Liberal Democratic Party won in the general election held in 2012, and Shinzo Abe became the prime minister. Prime Minister Abe has determined that a policy to strengthen the innovation is necessary. To maintain an economy, policies to intensify innovation have become more important. In June 2013, in addition to the Science and Technology Basic Plan based on the Science and Technology Basic Law, the "Science and Technology Innovation Strategy" was decided by the Cabinet, which embodies the integrated development of science and technology and innovation policy. After that, in line with this comprehensive Strategy and the Basic Law on Science and Technology, a comprehensive strategy on science and technology innovation has been formulated for each year.

\subsection{Science and Technology Innovation Strategy 2013}

The Council for Science and Technology formulated the "Science and Technology Innovation Strategy" (draft) in June 2013, and the draft was immediately decided by the Cabinet. In this strategy, we are aware that Japan is facing challenges such as economic revitalization, rapid decline in population and declining birthrate and aging population, global environmental issues, etc. Expected roles of science, technology and innovation are increasing. Particularly, it is necessary to concentrate on the potential of science, technology and innovation, focus on the current situation, and open to the future, in order to revive the economy, which is the greatest and pressing issue at present.

This "Science and Technology Innovation Strategy" shows the basic concept of science and technology and innovation with the Japanese economy and society in mind in 2030. The specific points of the Strategy are the following five.

- Comprehensive package of science and technology innovation policy oriented to problem solving

- The explicit description of roles and responsibilities of the industry-academia-government collaboration

- Combination of various policies such as budget and tax system, regulatory reform

- Expansion of the scope from the basic research to the applied research, not only the research and development stage from practical application, but also its upstream and downstream stages

- Evaluation and review measures through the annual PDCA process directly linked to the budget 


\subsection{Science and Technology Innovation Strategy 2014}

The Council for Science, Technology and Innovation added a new perspective based on the oneyear approach in line with the "Science and Technology Innovation Strategy" formulated in June 2013, and decided the "Science and Technology Innovation Strategy 2014".

In this comprehensive Strategy, the past years of policy results and the role of science and technology innovation in economic revitalization have been described, and the Strategy emphasized that to secure international competitiveness and achieve sustainable development. It is necessary to vitalize the basic science and technology innovation. The Strategy advocated "ICT", "Nanotechnology" and "Environmental technology" as three cross-cutting technologies to solve these policy issues. In addition, regarding the 2020 Olympics and Paralympic Tokyo Convention as an opportunity to transmit the results of research and development to the world, the Strategy stated that it will be used as a place to show off Japanese innovation.

Furthermore, as an environment creation suitable for science and technology innovation, the Strategy describes an effort to expand opportunities for diverse "challenge" and "interaction" of ambitious human resources. Above all, in "Forming an Innovation Hub with a Research and Development Corporation at the Core", seeds are created by the formation of an Innovation Hub by a public research institute and the bridging function, and the point is an effort to connect the results to practical realization and commercialization.

\subsection{Science and Technology Innovation Strategy 2015}

In June 2015, the next Science and Technology Innovation Strategy 2015, was formulated. In conjunction with the 5th Science and Technology Basic Plan, which will start in 2016, the Strategy aims to make the science and technology innovation policy more effective and efficient.

This Strategy describes the following three perspectives that should be emphasized in promoting science, technology and innovation policies.

- Anticipate "the era of great change" in which the process of value creation in economy and society changes significantly

- Take the lead in solving the complex and growing problems facing Japan and the world

- Induce a virtuous circle of human resources, knowledge and funds in addition to strengthening the foundation to respond to uncertain changes, and to make innovation sustainable

In order to smoothly launch the 5th Science and Technology Basic Plan, the following three policy areas were listed.

- Challenges for future industry creation and social change

- Promote science and technology innovation that contributes to regional revitalization

- Promote science and technology innovation by taking advantage of opportunities for the 2020 Tokyo Olympics and Paralympic Games

\subsection{Science and Technology Innovation Strategy 2016}

Based on that 2016 is the first year of the 5th Science and Technology Basic Plan, the Science and Technology Innovation Strategy 2016 was formulated.

In the Strategy, the following four items are listed to be examined further in the future, and to be 
put into force for concrete implementation.

- Deepening and promoting Society 5.0: the Strategy will strongly promote Society 5.0, and will balance Japan's industrial competitiveness and resolution of social issues. "Society 5.0" is a new economic society following hunting society, farming society, industrial society, and information society, and it integrates the cyber space and the physical space at a high level to balance economic development and social issues. It represents a human-centered society where people can live comfortable, vibrant and high quality lives for strengthening human resources including young people.

- Integrated promotion of university reforms and financial reforms: Strengthening the training of young people who must deal with them promptly, strengthening university reforms, and responding flexibly and accurately in times of major change where prospects for the future are difficult to stand.

- Establishing a virtuous circle system of human resources, knowledge and funds by promoting open innovation: Build a system in which innovations from Japan leading the world are continuously generated through full collaboration between industry, academia and government and creation and strengthening of venture companies.

- Strengthening the promotion function of science and technology innovation: Strengthen the promotion function of science and technology innovation including the strengthening of the command tower function, and effectively and flexibly execute the policies and measures positioned in the basic plan and this comprehensive strategy.

\subsection{Science and Technology Innovation Strategy 2017}

Based on that fiscal 2017 is the second year of the 5th Science and Technology Basic Plan, Science and Technology Innovation Strategy 2017 was formulated. In this Strategy, based on the 5th Science and Technology Basic Plan, next points should be addressed for 2017 to 2018, as an important matter in the effort.

- Realization of Society 5.0 ahead of the world

- Steady implementation of the Public-Private Investment Innovation Expansion Initiative

- Promotion of Society 5.0 and achievement of government R\&D investment targets

- Securing a research environment that produces excellent research centers and academic researches

- R\&D and human resources strengthening to boldly challenge to the future

- Building a platform to realize Society 5.0

\subsection{Integrated Innovation Strategy}

Since the Science and Technology Innovation Strategy was formulated in 2013, the Council for Science, Technology and Innovation has formulated an annual Science and Technology Innovation Strategy each year. In June 2018, integrated innovation strategy was established in the third year since the 5th Science and Technology Basic Plan was formulated. In this Strategy, innovations beyond imagination in the world progress, the game structure is transformed, and the policy on the extension of the past cannot overcome the world. 
The strategy presents the following three points as a source of knowledge.

- Development of data collaboration base for realization of Society 5.0

- Development of data base for open science

- Promotion of policy planning based on evidence and corporate administration of universities

Furthermore, the following five areas are listed as major areas in which efforts should be particularly strengthened.

- AI technology

- Biotechnology

- Environment and energy

- Safety and Security

- Agriculture

In the above Integrated Innovation Strategy, it was suggested that the establishment of "Integrated Innovation Strategy Promotion Council" is necessary from the viewpoint of strengthening the innovation related command tower's function. Therefore, the Integrated Innovation Strategy Promotion Council was established in the Cabinet to coordinate comprehensively several organizations such as the Council for Science, Technology and Innovation, the Advanced Information and Telecommunications Network Society Promotion Strategy Headquarters, the Intellectual Property Strategy Headquarters, the Health and Medical Strategy Promotion Headquarters, the Space Development Strategy Headquarters and the Integrated Ocean Policy Headquarters.

\section{The Basic Plans' Contribution to Science and Technology Activities in Japan}

\subsection{Clarification of the role of science and technology}

The largest contribution of past Science and Technology Basic Plans is assumed to be clearly describing what kind of role science and technology should accomplish in Japan's economy and society. Each Basic Plan describes Japan's position in the world at the time of the formulation, and also describes what science and technology activities will bring about. For example, in the 5th Basic Plan which is formulated most recently, four visions including "sustainable growth and development", "safety and security and life with high quality", "approach to the global-scale issue", "creation of intellectual property" are proposed, and it also describes how to achieve these visions with what kind of science and technology activities.

Today, science and technology is highly developed and its content is so subdivided. Therefore, each individual scientist or researcher tends to concentrate on his or her field only, and their attention to what their research and development activities means for society and the nation tends to decrease. The same is applicable for related government officials. Originally, government officials should act by considering the entire nation. However, it becomes common custom that they habitually place more priority to the direct interest of the Ministry or Institute they belong to. In that aspect, it is very important to clearly indicate the meaning of science and technology activity for the entire Japan at the time of establishing the Basic Plan. 


\subsection{Sharing the significance and meaning of science and technology}

For the general public, science and technology belongs to the field of specialists, and people tend to think that matters related to science and technology should be left to specialists. In the age when monarchs and nobles were patrons of scientists and provided research funds for them, it would be better for scientists not to be interfered by the public. However, today science and technology activities are supported by taxes from the public in most countries. Therefore, it is important to let the public have interest in science and technology, and make them think that taxes invested in science and technology are well spent. Furthermore, in the case of reforming various systems to promote science and technology, coordination with other social systems should be required. In such case the understanding from public also becomes very important.

The Basic Plan is formulated by sufficiently hearing opinions not only from persons concerned with science and technology, but also from related Ministries and Agencies in the government and politicians. Additionally, a public comment system has been introduced in order to hear opinions from the public directly. Furthermore, after the Council for Science, Technology and Innovation formulates the draft of the Basic Plan, this draft is decided as the Basic Plan by the Cabinet, and submitted to the Diet.

\subsection{Securing budget for science and technology}

For people concerned with science and technology, securing the budget for science and technology is important, and it is one of the important objectives of formulating this Basic Plan. In the past Science and Technology Basic Plan, the government's goal for research and development investment during the period of the plan was indicated. The goal for each Basic Plan was 17 trillion yen, 24 trillion yen, 25 trillion yen, 25 trillion yen and 26 trillion yen (listed from the 1st to the 5th in order). 26 trillion yen is approximately 236 billion US dollars when 1 US dollar is converted for 110 yen. In other mid to long term plans of the Japanese Government, the description of investment goal becomes very few due to resistance from the Ministry of Finance, but the Science and Technology Basic Plan still adheres to its rule of specifying investment goal. Note that the investment goals for 1st and 2nd Basic Plan are so different because the rule for which the budget item should be counted as science and technology investment was changed.

\subsection{Clarification of the order of priority}

It is also important that order of priority for investment on science and technology activities is clearly indicated in the Basic Plan. Concrete examples of which are the four important fields indicated in the 2nd Basic Plan. This policy became the basic concept in the scrutiny of the budget request conducted by the Ministry of Finance, which was considered to be accelerating the prioritization. However, it was pointed out that these four fields covered a considerably wide range, which included research that was not necessarily of imminent need. On the other hand, some obviously important research was not included in the four fields. After the 3rd Basic Plan, the weight on the concept of prioritization became gradually lessened. Nevertheless, even after the 3rd Basic Plan, "prioritization" has been an important key word in the Basic Plan. 


\subsection{Promotion of the system reform}

It is also important in the Basic Plan to propose reform for systems related to science and technology. For example, in the 1st Basic Plan, the "program to support 10,000 postdoctoral researchers", significant increase in competitive funds, and evaluation for research and development, were included. In the 2nd Basic Plan, promotion of administrative management of patents and other agendas were included. In the 3rd Basic Plan, setting a recruiting goal for female researchers and other agendas were included. In the 4th Basic Plan, reform of research and development institutes and other agendas were included.

In the Japanese government, the project enforcement Ministries and Agencies and competent authority for the system are often different, and when the enforcement Ministries and Agencies appeal the need of system reform, the competent authority for the system often shows disapproval from the point of the view of conformity around the whole nation. The Basic Plan is decided by the Cabinet, and it does not indicate immediate implementation of the content because of the resistance from competent authorities for systems. Nevertheless, discussions start because tasks are clearly indicated in the Basic Plan, and the start to discussion itself is very important.

\subsection{Promotion of cooperation among industry-university-government}

Even though the Basic Plan is decided by the government, its content refers to the relationship and cooperation with private parties including industry since the 1st Basic Plan. Japan is a democratic country of capitalism. Even if the government decides the direction of something, there is no obligation for private parties to follow it. However, science and technology activities are now spread so broadly that without cooperation beyond national universities and institutions, good results cannot be expected. Today the country's economic activity relies on a competitiveness of companies, and that competitiveness is mainly generated from the power of science and technology and innovation. Therefore, since the 1st Science and Technology Basic Plan, representatives of industry have participated in the formulation process. Also, measures for cooperation among industry-universitygovernment are actively described in the Basic Plan. Previously, private parties are not actively involved, but their sense of commitment is increasing recently due to the current innovation-oriented situation.

A qualitative shift was made in the 4th Basic Plan. In this Basic Plan, in addition to science and technology policies, innovation policies also began to be included, and the prioritization method was shifted from prioritization by field to prioritization of achievement. During the period of the 4th Basic Plan, the Council for Science and Technology Policy was changed to the Council for Science, Technology and Innovation in 2014. This trend becomes much stronger in the 5th Basic Plan. Except for basic science, all science and technology activities must be conducted with clearly defined exit strategy, and these activities must contribute to industry and society. In the formulation of the 5th Basic Plan, mutual cooperation with industry is attempted under the recognition that in order to accomplish economic revitalization and economic growth which are the top priority of the Shinzo Abe's administration, creation of science and technology innovation is essential. 


\section{Challenges}

\subsection{Budget target for research and development is not accomplished}

As written above, each Basic Plan has its goal for the government's investment amount on science and technology during the period covered by each plan. However, aside from the goal of the 1st Basic Plan, which is 17 trillion yen, no goal has been achieved.

The biggest reason for this is that since the collapse of the bubble economy in the 1990's, Japan has been in an economic downturn called "lost 20 years", and even after the credit expansion measure taken as the part of Abenomics, there has been no huge economic development. The Period of five Basic Plans corresponds with this era. Japan's financial situation has already been bad, and an increase in social security costs due to the aging society has placed an increased burden on it, resulting in a decrease in spending on other expenses including the budget for science and technology. Ministries and Agencies which promote science and technology complain that the growth of the budget for science and technology is less than that of other countries such as China.

However, according to the financial authority, the budget for science and technology is prioritized in comparison with other budgets such as the budget for public construction works. It is likely that Japan's economic growth rate will not change dramatically for the time being. Therefore, the Basic Plan has to be conducted with the presupposition that the growth rate continues to be low and the investment goal may not be accomplished.

\subsection{Strong authority of each Ministry}

In the Japanese government, the Minister for each Ministry has equal authority as that of the Prime Minister. Additionally, in principle, the Cabinet meeting which makes the final decision in the administration requires unanimous consent.

Therefore, no matter how hard the Minister in charge of the Council for Science, Technology and Innovation which makes the Basic Plan tries to coordinate Ministries, there is a case that Ministers of each Ministry object strongly, making the need for consistency with jurisdiction as an excuse. The above mentioned unaccomplished budget target is one of the typical example. The Ministry of Finance objects strongly from the viewpoint of a balanced budget. The same is applicable in the case of national universities.

National university's science and technology capability is very important in Japan's science and technology system. However, management of national universities is under the jurisdiction of the Ministry of Education, Culture, Sports, Science and Technology, and their approach from the viewpoint of the higher education system can be different in comparison with the approach from the viewpoint of promoting science and technology.

When approaches of two parties are different, they may fail to reach on an agreement and things written in the Basic Plan may not be carried out. In the case of system reform aiming for increasing the mobility of human resources or for other objectives, similar to mentioned above, the project enforcement Ministries and competent authority for the system may fail to reach an agreement and as a result, system reform may not be carried out. 
6.3. Not enough cooperation with interested parties outside of the government, such as industry

The Basic Plan is expected to refer to industry's science and technology activities, and leverage its potential. At the stage of formulation, consultation with industry association is made when needed, and also the association sends their representatives to the Basic Plan formulation committee.

However, after all, the Basic Plan is the plan of the government, and does not have authority to bind private parties. The government needs to have more financial support from industry in order to, for example, maintain and reinforce science and technology potential of national universities under such severe financial conditions, but matters are not progressing smoothly. 